\title{
Clinical applications of fibrinolytic inhibition in gynaecology
}

\author{
J BONNAR, J GUILLEBAUD, JM KASONDE, AND BL SHEPPARD
}

From the University of Dublin, Department of Obstetrics and Gynaecology, Trinity College Unit, Rotunda Hospital, Dublin 1, Ireland, the Margaret Pyke Centre, Middlesex Hospital, London WI, and the Ministry of Health, Ridgeway 110, Lusaka, Zambia

'In healthy menstruation the blood which is discharged does not coagulate; in the irregular or unhealthy it does....' This observation on the non-coagulability of menstrual blood was made by John Hunter in $1794 .{ }^{1}$ A similar observation was made by Bell in $1912^{2}$ on the composition of menstrual blood found in patients with haematocolpos. Over the past 20 years laboratory and clinical research has established that fibrinolysis is intimately concerned with the process of menstruation. The early studies of plasminogen activator showed high concentrations present in both the uterus and menstrual discharge. ${ }^{34}$ Extracts of secretory endometrium and endometrium from women with endometrial hyperplasia contained large amounts of activator. This established that the fluidity of menstrual blood was due to fibrin dissolution by plasmin produced by the activators of plasminogen. In a review of fibrinolysis Astrup ${ }^{5}$ suggested that increased local fibrinolytic activity might be the cause of excessive menstrual bleeding. This was supported by the findings of high concentrations of tissue activator in the fibrinolytic enzyme system not only in the endometrium but also in the myometrium of the uterus and in the glands of the cervical canal. ${ }^{6}$ ?

In a study of patients with excessive menstrual loss measured by an objective method, Rybo in $1966^{8}$ reported that the concentration of plasminogen activators in the endometrium was significantly higher than in women with normal menstrual loss. He also reported that the concentration increased in the premenstrual phase and was highest at the beginning of menstruation. High concentrations of fibrin/fibrinogen degradation products (FDP) are present in menstrual blood ${ }^{9}$ but no difference is found whether menstrual loss is normal or excessive. Basu' ${ }^{10}$ reported raised serum FDP levels in women with menorrhagia but others have found no relationship between the FDP level and the amount of menstrual loss. ${ }^{11}$

\section{Indications for fibrinolytic-inhibitor treatment}

The possible indications for treatment with fibrinolytic inhibitors are listed in Table 1.

\section{EXCESSIVE AND PROLONGED MENSTRUAL BLEEDING}

Soon after epsilon-aminocaproic acid (EACA) became available its use in women with dysfunctional uterine bleeding was investigated by Sato et al. ${ }^{12}$ They reported a decrease in menstrual bleeding in 29 out of 30 women. Successful treatment with EACA was subsequently reported ${ }^{13} 14$ and tranexamic acid (AMCA) was also found to be effective. ${ }^{15-17}$ Treating menorrhagia with EACA, AMCA, or PAMBA, Nilsson and Rybo ${ }^{18}$ found that menstrual loss was reduced by $49 \%, 53 \%$, and $36 \%$ respectively when measured by the alkaline haematin method. The dose of AMCA was 3-6 g/day for four days, starting after the onset of menstruation.

Table 1 Indications for treatment with fibrinolytic inhibitors in gynaecology and obstetrics

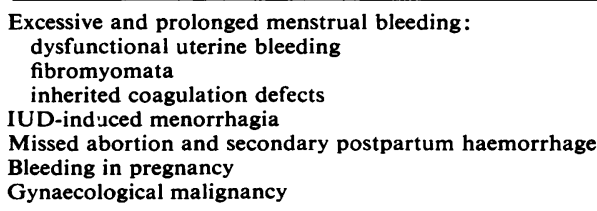

Profuse menstrual loss may also be a serious problem in that small group of women with congenital coagulation defects such as Von Willebrand's disease, factor V deficiency, or Glanzmann's thrombasthenia. It may start soon after the menarche and be related to the hormonal imbalance at this time associated with the early anovulatory cycles. Some patients may bleed seriously from the ovary at the time of ovulation. Fibrinolytic inhibitors reduce the 
profuse menstruation associated with congenital coagulation defects and in combination with progestogen therapy are usually effective in treatment. ${ }^{19}$

FIBRINOLYSIS AND MENSTRUAL BLEEDING WITH INTRAUTERINE DEVICES

Excessive and prolonged menstrual bleeding is the major complication of intrauterine devices (IUD) and the main reason for their discontinuation. The inert and copper devices increase menstrual loss and the amount seems to be related to the size of the IUD, the greatest increase occurring with the Lippes Loop and SAF-T-Coil and the least with the Copper 7 or Copper-T. The copper device, however, is associated with a longer menstrual flow than the other devices. ${ }^{20}$ Figures 1 and 2 show the changes in the amount and pattern of menstruation in women using the Lippes Loop or Copper 7.

Intense fibrinolytic activity can be demonstrated around IUDs removed from the uterus. ${ }^{21}$ Using an arbitrary scoring system, fibrinolytic activity was significantly higher in 56 women having the device withdrawn because of severe bleeding compared with 24 women not complaining of menorrhagia. ${ }^{21}$ Fibrin plates incorporating EACA showed an inhibition of fibrinolytic activity. Likewise, out of 35

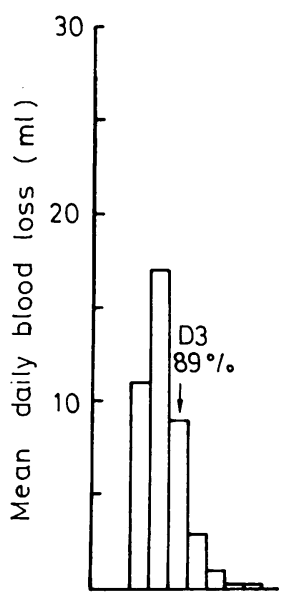

$1234567+$

Preinsertion

Menstrual period

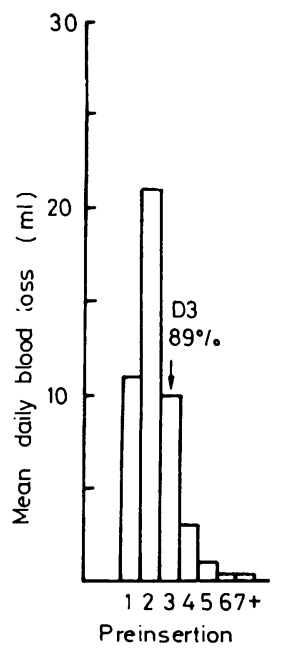

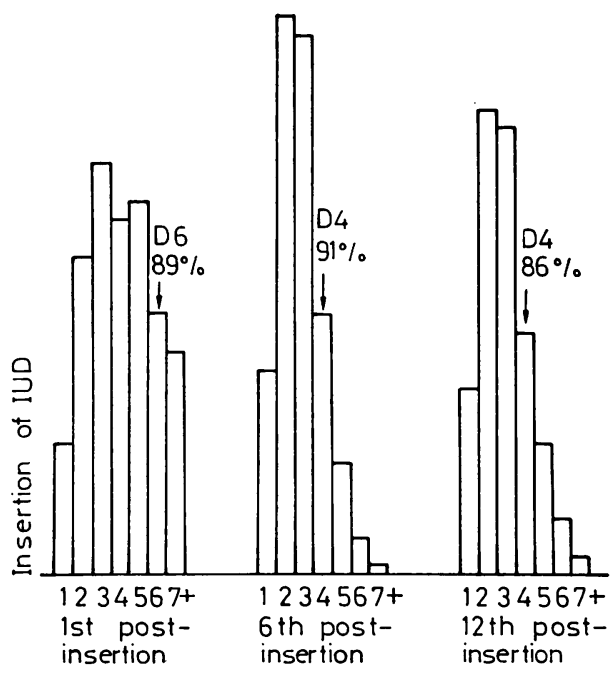

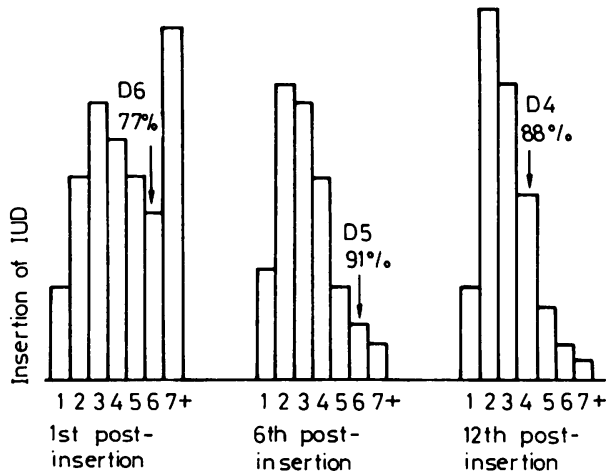

Fig. 1 Histograms of daily menstrual loss before and after insertion of Lippes Loop $D$ in 77 parous women. Before IUD insertion $89 \%$ of menstrual loss occurred by day 3. Increase and shift in distribution of menstrual loss is shown for 1st, 6th, and 12th menses after insertion.

Fig. 2 Histograms of daily menstrual loss before and after insertion of Copper 7 device in 91 parous women. Before IUD insertion $89 \%$ of menstrual loss occurred by day 3. Increase and shift in distribution of menstrual loss is shown for 1st, 6th, and 12th menses after insertion. 
devices examined on heated and unheated fibrin plates no lysis was found in 33 out of 35 plates suggesting that plasminogen activator as opposed to plasmin was the lytic factor.

Devices removed from women taking EACA showed reduced fibrinolytic activity. In 16 out of 20 women increased amounts of plasminogen activator were found in the endometrium after IUD insertion..$^{22}$ In a control study of 56 women EACA reduced the menstrual loss in IUD users by over $50 \% \cdot{ }^{23}$ The duration of intermenstrual bleeding was less in women taking EACA. ${ }^{23}$

\section{MISSED ABORTION AND SECONDARY}

POSTPARTUM HAEMORRHAGE

In these complications profuse bleeding from the uterus may continue despite the removal of retained products of conception and repair of soft tissue laceration. When such bleeding persists despite correction of any associated coagulation defect with fresh frozen plasma a fibrinolytic inhibitor such as EACA or AMCA may be given to counteract fibrinolysis in the uterus. Fibrinolytic inhibitors have also been used in abruptio placentae but benefit has not been established by controlled trial. ${ }^{24}$

\section{BLEEDING IN PREGNANCY}

Bleeding in pregnancy is associated with a substantial increase in perinatal mortality. Studies of the uteroplacental arteries have shown that fibrin deposition is a physiological component of the walls of the spiral arteries in late pregnancy ${ }^{25}$ (Fig. 3).

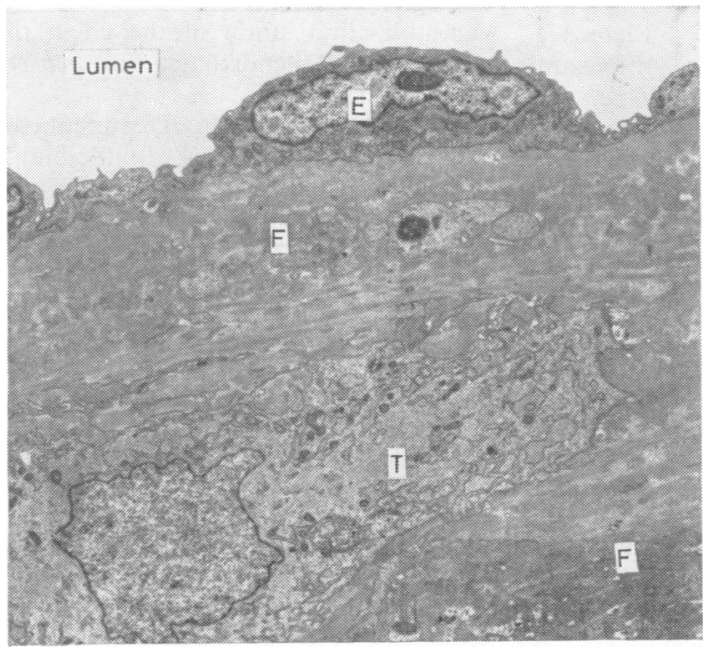

Fig. 3 Electron micrograph of part of wall of decidual spiral artery in late pregnancy. Below the endothelium $(E)$ a matrix containing fibrin $(F)$ surrounds the trophoblast cells $(T)$ of the media $(\times 6000)$.

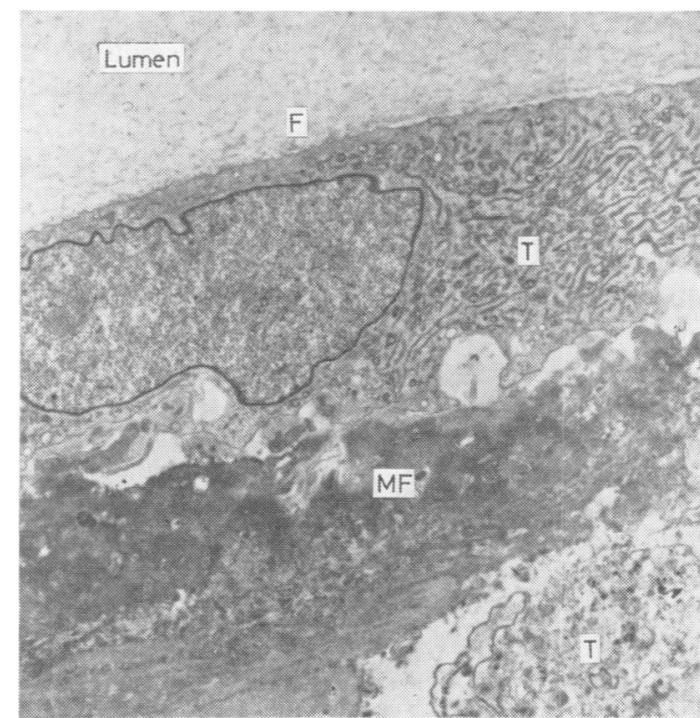

Fig. 4 Electron micrograph of part of decidual spiral artery in late pregnancy after application of a modified Todd's fibrin slide technique to demonstrate fibrinolytic activity. Overlying fibrin film $(F)$ remains closely opposed to the intimal trophoblast $(T)$ after 20 minutes' incubation. Fibrin $(M F)$ is also seen in the media below the trophoblast $(\times 7500)$.

The fibrinolytic activity of the vessel is also inhibited near the trophoblast cells present in the terminal parts of the spiral arteries ${ }^{26}$ (Fig. 4). Bleeding from the placental site in normally situated placentas may result from structural weakness and vascular defects due to defective fibrin deposition in some of the uteroplacental vessels. The use of a fibrinolytic inhibitor may therefore improve haemostasis at the placental site by augmenting the naturally occurring fibrinolytic inhibition produced by the placenta.

An effective method of treating placental bleeding in pregnancy might lower the high associated perinatal mortality and morbidity by reducing placental damage due to the bleeding and the incidence of premature labour. We have set up a strictly controlled trial in the Rotunda Hospital to evaluate the benefit of treatment with the fibrinolytic inhibitor tranexamic acid to the mother and to the baby when placental bleeding occurs between the 16-37th week of pregnancy.

\section{GYNAECOLOGICAL MALIGNANCY}

In a few patients with cervical and uterine carcinoma profuse bleeding may occur which does not respond to local haemostatic measures. EACA or AMCA can be used for the short-term control of such bleeding. In patients with ovarian carcinoma high concentra- 
tions of FDP are present which usually reflect the progress of the disease. The contribution of fibrinolysis to the spread of carcinoma in such tumours requires detailed research.

\section{SIDE EFFECTS OF FIBRINOLYTIC INHIBITORS}

The main problem of treatment with fibrinolytic inhibitors has been the side effects. Their incidence during treatment with EACA in 83 women treated over six months is shown in Table 2. Six women discontinued treatment because of the severity of the side effects. If the fibrinolytic inhibitor were given per vaginum or per rectum the incidence of gastrointestinal side effects might be reduced. This requires further investigation. The incidence of side effects with tranexamic acid seem to be much less than with EACA.

Table 2 Nature and incidence of side effects over six menstrual cycles in 83 women taking EACA by mouth

\begin{tabular}{ll}
\hline Side effect & Incidence $(\%)$ \\
\hline Nausea & 45 \\
Abdominal discomfort & 36 \\
Headache & 30 \\
Dizziness & 29 \\
Diarrhoea & 18 \\
Vomiting & 12 \\
Others & 10 \\
\hline
\end{tabular}

\section{Conclusion}

Fibrinolytic inhibitors have an important role in the management of profuse menstrual bleeding due to dysfunctional bleeding, IUD, and inherited coagulation defects. Their value in the bleeding complications of pregnancy remain in doubt and warrants further research by controlled studies. The role of fibrinolysis in the spread of uterine and ovarian cancer should also be investigated.

This work was supported by the World Health Organisation (Special Programme for Research in Human Reproduction), Pathfinder Fund, and the Friends of the Rotunda, Dublin.

\section{References}

${ }^{1}$ Hunter J. A treatise on the blood, inflammation and gun-shot wound. London: Nicoll, 1794.

2 Bell WB. Further investigations into the chemical composition of menstrual fluid. J Obstet Gynaec Br Emp 1912;21:209-15.

${ }^{3}$ Albrechtsen OK. The fibrinolytic activity of the human endometrium. Acta Endocrinol (Kbh) 1956;23:207-18.

4 Albrechtsen OK. The fibrinolytic activity of human tissue. Br J Haematol 1957;3:284-91.

${ }^{5}$ Astrup T. The haemostatic balance. Thromb et Diath Haem 1958;2:347-57.

- Weiss G, Beller FK. Tissue activator of the fibrinolytic enzyme in the female reproductive system. Obstet Gynec 1969;34:809-19.

${ }^{7}$ Glas-Greenwalt P, Beller FK, Astrup T. Comparative assays of tissue plasminogen activator in myometrium, cervix, and fibromyomas of the human uterus. Am J Obstet Gynecol 1971;110:721-5.

${ }^{8}$ Rybo G. Plasminogen activators in the endometrium. II. Clinical aspects. Acta Obst et Gynec Scand 1966; 45:429-50.

${ }^{9}$ Hahn L. On fibrinolysis and coagulation during parturition and menstruation. Acta Obst Gynecol Scand (Suppl) 1974;53:28.

${ }^{10}$ Basu HK. Fibrin degradation products in sera of women with normal menstruation and menorrhagia. Br Med J 1970;1:74-5.

${ }^{11}$ Cole SK, Clarkson AR. Menstrual blood loss and fibrin degradation products. Br Med J 1972;1:78-9.

${ }^{12}$ Sato S, Ishibashi Y, Endo T, Watanabe T, Nakajima K. Clinical use of $\epsilon$-amino-N-caproic acid on metropathia haemorrhagica. Keio J Med 1959;8: 267-78.

${ }^{13}$ Nilsson IM, Björkman SE, Andersson L. Clinical experiences with $\epsilon$-aminocaproic acid ( $\epsilon$-ACA) as an antifibrinolytic agent. Acta Med Scand 1961; 170:487-509.

${ }^{14}$ Nilsson L, Rybo G. Treatment of menorrhagia with epsilon-aminocaproic acid. Acta Obst Gynecol Scand 1965;44:467-73.

${ }^{15}$ Nilsson L, Rybo G. Treatment of menorrhagia with an antifibrinolytic agent, tranexamic acid (AMCA). A double-blind investigation. Acta Obst Gynecol Scand $1967 ; 46: 572-80$.

${ }^{16}$ Vermylen J, Verhaegen-Declercq ML, Verstraete M, Fierens F. A double-blind study of the effect of tranexamic acid in essential menorrhagia. Thromb et Diath Haem 1968;20:583-7.

${ }^{17}$ Callender ST, Warner GT, Cope E. Treatment of menorrhagia with tranexamic acid. A double-blind trial. Br Med J 1970;4:214-6.

${ }^{18}$ Nilsson L, Rybo G. Treatment of menorrhagia. Am J Obstet Gynecol 1971;110:713-20.

${ }^{19}$ Nilsson IM, Björkman SE. Experience with epsilonaminocaproic acid (EACA) in the treatment of profuse menstruation. Acta Med Scand 1965;177: 445-57.

${ }^{20}$ Guillebaud J, Bonnar J. Longer though lighter menstrual and intermenstrual bleeding with copper as compared to inert intrauterine devices. $\mathrm{Br} \mathrm{J}$ Obstet Gynaecol 1978;85:707-12.

${ }^{21}$ Bonnar J, Kasonde JM, Haddon M, Hassanein MK, Allington MJ. Fibrinolytic activity in utero and bleeding complications with intrauterine devices. Br J Obstet Gynaecol 1976;83:160-4.

${ }^{22}$ Kasonde JM, Bonnar J. Effect of ethamsylate and aminocaproic acid on menstrual blood loss in women using intrauterine devices. $\mathrm{Br}$ Med $J$ 1975; 4:21-2.

${ }^{23}$ Kasonde JM, Bonnar J. Aminocaproic acid and men- 
strual loss in women using intrauterine devices. Br Med J 1975;4:17-9.

${ }^{24}$ Astedt B, Nilsson IM. Recurrent abruptio placentae treated with the fibrinolytic inhibitor tranexamic acid. Br Med J 1978;1:756-7.

${ }^{25}$ Bonnar J, Sheppard BL. The vascular supply of the placenta in normal and abnormal pregnancy. In: Blaustein A, ed. Pathology of the female genital tract. New York: Springer-Verlag, 1977:673-87.

${ }^{26}$ Sheppard BL, Bonnar J. Fibrinolysis in decidual spiral arteries in late pregnancy. Thromb Haemostas 1978; 39:751-8 